$\boldsymbol{L E X}$. Revista de Investigaciones en Ciencias Jurídicas julio-septiembre-2018

Volumen 1, Número 1

pp. $29-46$

\title{
Bloque de constitucionalidad y control de convencionalidad en Bolivia
}

\section{Constitutionality and conventionality control block in Bolivia}

\author{
Alan E. Vargas Lima \\ alanvargas4784@gmail.com \\ Miembro de la Academia Boliviana de Estudios Constitucionales, Bolivia
}

Recibido: Abril 2018 / Revisado: Mayo 2018 / Aceptado: Junio 2018/ Publicado: Julio 2018

\begin{abstract}
RESUMEN
El presente trabajo pretende mostrar el intenso desarrollo doctrinal y jurisprudencial del tema propuesto, partiendo de la premisa esencial de que la actual configuración constitucional del Bloque de Constitucionalidad, constituye una reivindicación de las líneas jurisprudenciales establecidas con bastante anterioridad por el Tribunal Constitucional boliviano; ello para luego examinar el redimensionamiento del mismo bloque en el Estado Constitucional de Derecho, a la luz del pluralismo y la interculturalidad como nuevos paradigmas en la interpretación, a través de la inserción de valores plurales y principios supremos rectores del orden constitucional vigente en el país, haciendo especial referencia a los principales pronunciamientos del Sistema Interamericano de Protección de los Derechos Humanos, ante su escaso conocimiento por parte de los administradores de justicia, y su nula aplicación en la resolución de conflictos concretos.
\end{abstract}

Palabras clave: Bloque de constitucionalidad; control plural de constitucionalidad; control de convencionalidad; jurisprudencia interamericana; derechos humanos

\begin{abstract}
To verify the doctrinal and jurisprudential development of the proposed theme, it will depart from the premise of the current constitutional setup of constitutionality block constitutes a claim of the jurisprudential lines established long before by the Bolivian Constitutional Court, to then examine the downsizing of the same block in the constitutional rule of law, in the light of pluralism and multiculturalism as new paradigms in the interpretation, through the inclusion of plural values and Supreme principles of the constitutional order in force in the country, with particular reference to the major pronouncements of the Inter-American system for the protection of human rights.
\end{abstract}

Key words: Block of constitutionality; plural control of constitutionality; control of conventionality; interamerican jurisprudence; human rights 
INTRODUCCIÓN

Se debe comenzar recordando al jurista español Francisco Rubio Llorente (19302016), quien en su estudio introductorio al Bloque de Constitucionalidad, precisaba que en la doctrina de Francia -país en donde se originó el Bloc de Constitutionnalité, por una resolución del Consejo Constitucional francés, el 8 de julio de 1966- se utiliza este término para designar al conjunto de normas integrado por la Constitución y, por remisión del Preámbulo de ésta, la Declaración de Derechos del Hombre y del Ciudadano de 1789 y el Preámbulo de la Constitución de 1946, que es realmente también una declaración de derechos, sobre todo de carácter social- que el Consejo Constitucional aplica en el control previo de constitucionalidad de las normas (RUBIO LLORENTE, 1991; 105).

Sobre la base de lo anterior, es posible deducir que son parte del Bloque de Constitucionalidad aquellas normas, principios y valores que, sin ser parte del texto constitucional, por disposición o mandato de la propia Constitución, se integran a ella con la finalidad de llevar a cabo el control de constitucionalidad. Así, una síntesis de estos criterios, ahora se encuentra plasmada precisamente en el texto de la Constitución Política del Estado Plurinacional de Bolivia, cuando dispone que "el bloque de constitucionalidad está integrado por los Tratados y Convenios internacionales en materia de Derechos Humanos y las normas de Derecho Comunitario, ratificados por el país. (...)" (Artículo 410, parágrafo II constitucional). Éste precepto referido al Bloque de Constitucionalidad, ciertamente constituye una reivindicación de las líneas jurisprudenciales establecidas con bastante anterioridad por la jurisprudencia constitucional, dado que el Tribunal Constitucional, en su primera época, en los Fundamentos Jurídicos de la Sentencia Constitucional № 0045/2006 de 2 de junio, había precisado que la teoría del bloque de constitucionalidad surgió en Francia, extendiéndose luego a los países europeos, siendo asimilada en Latinoamérica; entendiendo que dicha teoría, expone que aquellas normas que no forman parte del texto de la Constitución, pueden formar parte de un conjunto de preceptos que por sus cualidades intrínsecas se deben utilizar para develar la constitucionalidad de una norma legal; así, las jurisdicciones constitucionales agregan, para efectuar el análisis valorativo o comparativo, a su Constitución, normas a las que concede ese valor supralegal que las convierte en parámetro de constitucionalidad.

De ahí que, la jurisdicción constitucional boliviana ha concedido al bloque de constitucionalidad un alcance perceptible en la Sentencia Constitucional № 1420/2004-R, de 6 de septiembre, estableciendo lo siguiente: “(...) conforme ha establecido este Tribunal Constitucional, a través de su jurisprudencia, los tratados, convenciones o declaraciones internacionales sobre derechos humanos a los que se hubiese adherido o suscrito y ratificado el Estado boliviano forman parte del bloque de constitucionalidad y los derechos consagrados forman parte del catálogo de los derechos fundamentales previstos por la Constitución."; ... a través de los recursos de hábeas corpus y amparo constitucional conforme corresponda". De tal manera, la jurisprudencia glosada, se deduce que el bloque de constitucionalidad en Bolivia lo conforman, además del texto de la Constitución, los tratados, las declaraciones y convenciones internacionales en materia de derechos humanos ratificados; entonces, queda claro que no todo tratado, declaración, convención o instrumento internacional es parte del bloque de constitucionalidad, sino sólo aquellos que habiendo sido previamente ratificados por el Estado boliviano, estén destinados a la promoción, protección y vigencia de los derechos humanos, constituyéndose en un parámetro efectivo de 
constitucionalidad. En este sentido, el estudio realizado estuvo sustentado en una investigación documental, de nivel descriptivo y utilizado como técnica de recolección de información, la revisión de textos jurídicos y jurisprudencia respectivas al tema expuesto.

\section{METODOLOGÍA}

El estudio realizado estuvo sustentado en una investigación documental, de nivel descriptivo y utilizado como técnica de recolección de información, la revisión de textos jurídicos, jurisprudencias y sentencias respectivas al Bloque de Constitucionalidad y Control de Convencionalidad en Bolivia; realizando así un análisis situacional en su desarrollo y aplicación.

\section{RESULTADOS Y DISCUSIÓN}

\section{Redimensionamiento del bloque de constitucionalidad en Bolivia}

Ampliando los criterios jurisprudenciales precedentemente expuestos, y respecto a los elementos del Sistema Interamericano de Derechos Humanos que también conforman el Bloque de Constitucionalidad en Bolivia, el Tribunal Constitucional pronunció una Sentencia Constitucional, a través de la cual entendió que los elementos normativos y las decisiones jurisdiccionales que emanen de este sistema no son aislados e independientes del sistema legal interno, dado que la efectividad en cuanto a la protección de los derechos fundamentales, solamente está garantizada en tanto y cuanto el orden interno asuma, en lo referente a su contenido, los alcances $y$ efectos de estas normas $y$ decisiones emergentes del Sistema Interamericano de Protección de Derechos Humanos. En este sentido, sostuvo lo siguiente:

"En efecto, la doctrina del bloque de constitucionalidad reconocida por el art. 410 de la CPE, contempla como parte del mismo a los Tratados
Internacionales referentes a Derechos Humanos,...el Estado Plurinacional de Bolivia.

El Pacto de San José de Costa Rica, como norma componente del bloque de constitucionalidad, está constituido por tres partes esenciales, estrictamente...)".

Finalmente, el Tribunal concluyó estableciendo en su pronunciamiento, que al ser la Corte Interamericana de Derechos Humanos el último y máximo garante en el plano supranacional del respeto a los Derechos Humanos, el objeto de su competencia y las decisiones que en ejercicio de ella emanan, constituyen piedras angulares para garantizar efectivamente la vigencia del "Estado Constitucional", que contemporáneamente se traduce en el "Estado Social y Democrático de Derecho", y que tiene como uno de sus ejes principales, entre otros, precisamente la vigencia de los Derechos Humanos y la existencia de mecanismos eficaces que los hagan valer. Es por esta razón, que las Sentencias emanadas de la Corte IDH, ahora también forman parte del bloque de constitucionalidad y fundamentan no solamente la actuación de los agentes públicos, sino también subordinan en cuanto a su contenido a toda la normativa infraconstitucional vigente.

En resumen, conforme se ha detallado en la Declaración Constitucional Plurinacional № 0003/2013 de fecha 25 de abril de 2013, el bloque de constitucionalidad imperante en el Estado Plurinacional de Bolivia, está compuesto por los siguientes compartimentos: 1) La Constitución como norma positiva; 2) Los tratados internacionales referentes a Derechos Humanos; y 3) Las Normas Comunitarias; sin embargo, en el marco de una interpretación progresiva, acorde al principio de unidad constitucional y enmarcada en las directrices principistas del Estado Plurinacional de Bolivia, debe establecerse además que los valores plurales 
supremos del Estado Plurinacional de Bolivia, como ser el vivir bien, la solidaridad, la justicia, la igualdad material, entre otros, forman parte del bloque de constitucionalidad en un componente adicional, el cual se encuentra amparado también por el Principio de Supremacía Constitucional.

Conforme a lo expuesto, se puede inferir que la jurisprudencia constitucional ha realizado un redimensionamiento del bloque de constitucionalidad y del Estado Constitucional de Derecho a la luz del pluralismo y la interculturalidad, dado que la inserción en el Bloque de Constitucionalidad de valores plurales y principios supremos rectores del orden constitucional, tiene una relevancia esencial, ya que merced al principio de supremacía constitucional aplicable al bloque de constitucionalidad boliviano, operará el fenómeno de constitucionalización, no solamente en relación a normas supremas de carácter positivo, sino también en relación a valores y principios supremos rectores del orden constitucional, aspecto, que en definitiva consolidará el carácter axiomático de la Constitución Política del Estado aprobada en 2009.

En este redimensionamiento del bloque de constitucionalidad y del Estado Constitucional de Derecho, se colige que a la luz del vivir bien, la justicia y la igualdad como principios y valores plurales supremos que forman parte del bloque de constitucionalidad imperante, irradiarán de contenido todos los actos de la vida social, consagrando así los postulados propios del Estado Constitucional de Derecho (Cfr. Sentencia Constitucional Plurinacional № 0683/2013, de fecha 3 de junio de 2013).

En definitiva, y en una interpretación sistemática, extensiva y acorde con el valor axiomático de la Constitución desarrollado por la jurisprudencia constitucional, es posible concluir que el bloque de constitucionalidad imperante en el Estado Plurinacional de Bolivia, está compuesto -de manera enunciativa y no limitativa- por los siguientes elementos: i) La Constitución como norma jurídica; ii) Los tratados y convenciones internacionales destinados a la protección de los Derechos Humanos; iii) las normas de Derecho Comunitario ratificadas por el país; iv) las sentencias emitidas por la Corte Interamericana de Derechos Humanos como máximo garante del respeto a los derechos humanos en el plano supranacional; y, v) los principios $y$ valores plurales supremos inferidos del carácter intercultural y del pluralismo axiomático contemplado en el orden constitucional.

\section{La doctrina jurisprudencial del Control de Convencionalidad}

En mérito al entendimiento jurisprudencial establecido a partir de la SC 110/2010-R de 10 de mayo, en sentido de que las Sentencias de la Corte Interamericana de Derechos Humanos son vinculantes para el Estado Plurinacional de Bolivia y forman parte del bloque de constitucionalidad, corresponde hacer una breve referencia a la naturaleza y alcance de la doctrina del control de convencionalidad establecida precisamente por la jurisprudencia interamericana, para su aplicación en el contexto boliviano.

A este efecto, se debe iniciar, señalando que el "control de convencionalidad", es un tema que ha adquirido bastante notoriedad en los últimos años, pero que, sin embargo, data desde la vigencia misma de la Convención Americana sobre Derechos Humanos, dado que ha sido y es, precisamente, el control que usualmente ha realizado y realiza la Corte Interamericana de Derechos Humanos (Corte IDH) en cada una de sus sentencias, cuando al juzgar las violaciones a la Convención Americana sobre Derechos Humanos (CADH) cometidas por los actos u omisiones de los Estados, ha tenido que confrontar las normas de la misma con las previsiones del derecho interno, de manera que en los casos en los cuales ha encontrado que estas son contrarias 
o incompatibles con aquella, ha ordenado a los Estados realizar la corrección de la "inconvencionalidad", por ejemplo modificando la norma cuestionada.

Así también, es el control que han ejercido y ejercen los jueces o tribunales nacionales, cuando han juzgado la validez de los actos del Estado, al confrontarlos no sólo con la Constitución respectiva, sino con el elenco de derechos humanos y de obligaciones de los Estados contenidos en la Convención Americana, o al aplicar las decisiones vinculantes de la Corte Interamericana, decidiendo en consecuencia, conforme a sus competencias, la anulación de las normas nacionales o su desaplicación en el caso concreto. Es así que, en el ámbito de los derechos humanos, tuvieron que pasar casi cuarenta años desde que la Convención fuera suscrita (1969), para que gracias a la importante conceptualización efectuada en el año 2003 por el entonces juez de la Corte IDH, Sergio García Ramírez, se captara en sus propios contornos el control que la propia Corte y los jueces y tribunales nacionales venían ejerciendo con anterioridad.

Por tanto, en esta materia, solamente existirían dos cuestiones relativamente nuevas (BREWER-CARÍAS, 2012): a) la afortunada acuñación de un término como ha sido el de "control de convencionalidad" que Sergio García Ramírez propuso en su Voto Razonado a la sentencia del Caso Myrna Mack Chang vs. Guatemala, de 25 de noviembre de 2003; y b) la clarificación de que dicho control de convencionalidad se efectúa en dos vertientes o dimensiones: por un lado a nivel internacional por la Corte Interamericana, y por el otro, en el orden interno de los países, por los jueces y tribunales nacionales.

En una reciente publicación de sus Votos particulares, el ex juez de la Corte IDH, Sergio García Ramírez, explica estas dimensiones, en la siguiente forma:

"El control propio, original o externo de convencionalidad recae en el tribunal supranacional llamado a ejercer la confrontación entre actos domésticos y disposiciones convencionales, en su caso, con el propósito de apreciar la compatibilidad entre aquéllos y éstas -bajo el imperio del Derecho internacional de los derechos humanos- y resolver la contienda a través de la sentencia declarativa y condenatoria que, en su caso, corresponda. En definitiva, ese control incumbe, original y oficialmente, a la Corte Interamericana de Derechos Humanos, cuando se trata de examinar casos de los que aquélla conoce y a los que aplica normas conforme a su propia competencia material. (...)

Ahora bien, cuando menciono el control interno de convencionalidad me refiero a la potestad conferida o reconocida a determinados órganos jurisdiccionales -o a todos los órganos jurisdiccionales- para verificar la congruencia entre actos internos -así esencialmente, las disposiciones domésticas de alcance general: constituciones, leyes, reglamentos, etcétera- con las disposiciones del Derecho internacional (que en la hipótesis que me interesa reduciré a una de sus expresiones: el Derecho internacional de los ...con el ordenamiento internacional". (García Ramírez, 2015; p. 26-27)

Estas dos vertientes, fueron explicadas por el entonces juez de la Corte IDH, Sergio García Ramírez, en el Voto razonado emitido con relación a la sentencia del Caso Tibi vs. Ecuador, cuando efectuó una comparación entre el control de constitucionalidad y el control de convencionalidad, considerando que la función de la Corte Interamericana, se asemejaba a la de los Tribunales Constitucionales cuando juzgan la inconstitucionalidad de las leyes y demás actos normativos conforme a las reglas, principios y valores constitucionales; agregando que dicha Corte, analiza los actos 
de los Estados que llegan a su conocimiento "en relación con normas, principios y valores de los tratados en los que funda su competencia contenciosa"; y que si bien "los tribunales constitucionales controlan la 'constitucionalidad', el tribunal internacional de derechos humanos resuelve acerca de la 'convencionalidad' de esos actos" (Caso Tibi vs. Ecuador. Excepciones Preliminares, Fondo, Reparaciones y Costas. Sentencia de 7 de septiembre de 2004).

Por otra parte, en cuanto al control de constitucionalidad que realizan los órganos jurisdiccionales internos, de acuerdo con lo expresado por el mismo García Ramírez en la referida Sentencia, estos "procuran conformar la actividad del poder público -y, eventualmente, de otros agentes sociales- al orden que entraña el Estado de Derecho en una sociedad democrática", en cambio "el tribunal interamericano, por su parte, pretende conformar esa actividad al orden internacional acogido en la Convención fundadora de la jurisdicción interamericana y aceptado por los Estados partes en ejercicio de su soberanía".

A raíz de estas reflexiones, quedó claro en el mundo internacional de los derechos humanos que bajo la misma denominación de "control de convencionalidad" se han venido ejerciendo dos tipos de controles, por dos tipos de órganos jurisdiccionales distintos ubicados en niveles diferentes: uno en el ámbito internacional y otro en el ámbito nacional, y con efectos jurídicos completamente distintos, lo que amerita realizar algunas puntualizaciones sobre uno y otro, a efecto de poder precisar con mayor detalle, algunas perspectivas del control (difuso) de convencionalidad en la tutela judicial efectiva de los derechos fundamentales en Bolivia.

\section{Surgimiento y desarrollo de la doctrina jurisprudencial del Control de Convencionalidad}

La doctrina del "control de convencionalidad" surge en el año 2006, en el Caso Almonacid Arellano vs. Chile, ocasión en la cual la Corte IDH precisó lo siguiente:

"123. La descrita obligación legislativa del artículo 2 de la Convención tiene también la finalidad de facilitar la función del Poder Judicial de tal forma que el aplicador de la ley tenga una opción clara de cómo resolver un caso particular. Sin embargo, cuando el Legislativo falla en su tarea de suprimir $y / o$ no adoptar leyes contrarias a la Convención Americana, el Judicial permanece vinculado al deber de garantía establecido en el artículo 1.1 de la misma $y$, consecuentemente, debe abstenerse de aplicar cualquier normativa contraria a ella. El cumplimiento por parte de agentes o funcionarios del Estado de una ley violatoria de la Convención produce responsabilidad internacional del Estado, y es un principio básico del derecho de la responsabilidad internacional del Estado, recogido en el Derecho Internacional de los Derechos Humanos, en el sentido de que todo Estado es internacionalmente responsable por actos u omisiones de cualesquiera de sus poderes u órganos en violación de los derechos internacionalmente consagrados, según el artículo 1.1 de la Convención Americana.

124. La Corte es consciente que los jueces y tribunales internos están sujetos al imperio de la ley y, por ello, están obligados a aplicar las disposiciones vigentes en el ordenamiento jurídico. Pero cuando un Estado ha ratificado un tratado internacional como la Convención Americana, sus jueces, como parte del aparato del Estado, también están sometidos a ella, lo que les obliga a velar porque los efectos de las disposiciones de la Convención no se vean mermadas por la aplicación de leyes contrarias a su objeto y fin, y que desde un inicio carecen de efectos jurídicos. En otras palabras, el Poder 
Judicial debe ejercer una especie de "control de convencionalidad" entre las normas jurídicas internas que aplican en los casos concretos y la Convención Americana sobre Derechos Humanos. En esta tarea, el Poder Judicial debe tener en cuenta no solamente el tratado, sino también la interpretación que del mismo ha hecho la Corte Interamericana, intérprete última de la Convención Americana. (Subrayado añadido).

125. En esta misma línea de ideas, esta Corte ha establecido que "según el derecho internacional las obligaciones que éste impone deben ser cumplidas de buena fe y no puede invocarse para su incumplimiento el derecho interno". Esta regla ha sido codificada en el artículo 27 de la Convención de Viena sobre el Derecho de los Tratados de 1969." (Caso Almonacid Arellano vs. Chile. Excepciones Preliminares, Fondo, Reparaciones y Costas. Sentencia de 26 de septiembre de 2006. Serie C No. 154, párr. 123 a 125).

El citado precedente -agrega el jurista mexicano (Ferrer Mac-Gregor, 2011; 531622) -, fue reiterado con ciertos matices, dos meses después, en el Caso Trabajadores Cesados del Congreso (Aguado Alfaro y otros) vs. Perú. En efecto, en este fallo se invoca el criterio del Caso Almonacid Arellano sobre el "control de convencionalidad" y lo "precisa" en dos aspectos: (i) procede "de oficio" sin necesidad de que las partes lo soliciten; y (ii) debe ejercerse dentro del marco de sus respectivas competencias y de las regulaciones procesales correspondientes, considerando otros presupuestos formales y materiales de admisibilidad y procedencia.

Entonces, de acuerdo a lo anteriormente expuesto, se puede inferir que desde el Caso Almonacid Arellano vs. Chile, la Corte IDH ha ido precisando el contenido y alcance del concepto de control de convencionalidad en su jurisprudencia, para llegar a un concepto complejo que comprende los siguientes elementos o características: a) Consiste en verificar la compatibilidad de las normas $y$ demás prácticas internas con la CADH, la jurisprudencia de la Corte IDH y los demás tratados interamericanos de los cuales el Estado sea parte; b) Es una obligación que corresponde a toda autoridad pública en el ámbito de sus competencias; $\boldsymbol{c})$ Para efectos de determinar la compatibilidad con la CADH, no sólo se debe tomar en consideración el tratado, sino que también la jurisprudencia de la Corte IDH y los demás tratados interamericanos de los cuales el Estado sea parte; d) Es un control que debe ser realizado ex officio por toda autoridad pública; y e) Su ejecución puede implicar la supresión de normas contrarias a la CADH o bien su interpretación conforme a la $C A D H$, dependiendo de las facultades de cada autoridad pública. (Corte Interamericana De Derechos Humanos, 2014).

Desde entonces se ha venido consolidando la esencia de esta doctrina, al aplicarse en los casos contenciosos siguientes: La Cantuta vs. Perú (2006); Boyce y otros vs. Barbados (2007); Heliodoro Portugal vs. Panamá (2008); Rosendo Radilla Pacheco vs. Estados Unidos Mexicanos (2009). Posteriormente, los alcances del control de convencionalidad, fueron reiterados en las siguientes sentencias: Manuel Cepeda Vargas vs. Colombia (2010); Comunidad Indígena Xákmok Kásek vs. Paraguay (2010); Fernández Ortega y Otros vs. México (2010); Rosendo Cantú y Otra vs. México (2010); Ibsen Cárdenas e Ibsen Peña vs. Bolivia (2010); Vélez Loor vs. Panamá (2010); Gomes Lund y Otros (Guerrilha do Araguaia) vs. Brasil (2010); Cabrera García y Montiel Flores vs. México (2010).

Al año siguiente, los estándares sobre el control de convencionalidad fueron citados en los siguientes casos: Gelman vs. Uruguay (2011), Chocrón Chocrón vs. Venezuela (2011), López Mendoza vs. Venezuela (2011), y Fontevecchia y D'amico vs. Argentina (2011). 
Un año más tarde, con mayores y menores matices, la doctrina jurisprudencial sobre el control de convencionalidad, fue reiterada en los siguientes casos: Atala Riffo y Niñas vs. Chile (2012), Furlan y Familiares vs. Argentina (2012), Masacres de Río Negro vs. Guatemala (2012), Masacres de El Mozote y lugares aledaños vs. El Salvador (2012), Gudiel Álvarez y otros ("Diario Militar") vs. Guatemala (2012), y Masacre de Santo Domingo vs. Colombia (2012). Asimismo, al año siguiente, la línea jurisprudencial fue reiterada en tres sentencias: Mendoza y otros vs. Argentina (2013), García Cruz y Sánchez Silvestre vs. México (2013), y J. vs. Perú (2013).

En el año 2014, la Corte incluyó su jurisprudencia sobre el control de convencionalidad en cuatro sentencias, en los casos: Liakat Ali Alibuk vs. Surinam, Norín Catriman $y$ otros (Dirigentes, miembros $y$ activista del pueblo indígena Mapuche) vs. Chile, Personas dominicanas y haitianas expulsadas vs. República Dominicana, y Rochac Hernández y otros vs. El Salvador.

De igual manera, en el año 2015, la jurisprudencia sobre el control de convencionalidad fue reiterada en cuatro sentencias: López Lone y otros vs. Honduras, Ruano Torres y otros vs. El Salvador, Comunidad Garífuna de Punta Piedra y sus miembros vs. Honduras, y García Ibarra y otros vs. Ecuador (Ibáñez Rivas, 2017; 51-68).

\section{Fundamento normativo del Control de Convencionalidad}

Para poder profundizar en el análisis del control de convencionalidad, se requiere precisar cuál es el origen de su obligatoriedad, es decir, su fundamento; lo cual resulta imprescindible para entender la importancia de realizar dicho control y para señalar que su ausencia implica que los Estados pueden comprometer su responsabilidad internacional.

Así, vemos que el control de convencionalidad encuentra su fundamento en las fuentes normativas de las cuales emanan las obligaciones de los Estados, a través de la lectura conjunta de los artículos 1.1, 2 y 29 de la CADH.

De la lectura integrada de dichos artículos -agrega Claudio Nash-, se desprende que la protección de los derechos humanos debe ser guía en la actuación de los Estados y que éstos deben tomar todas las medidas para asegurar el respeto, la protección y la promoción de dichos derechos. En este sentido, desde esta comprensión se ha concebido el concepto de control de convencionalidad, entendido como la obligación que tienen los jueces de cada uno de los Estados Partes de efectuar no sólo un control de legalidad y de constitucionalidad en los asuntos de su competencia, sino de integrar en el sistema de sus decisiones, las normas contenidas en la CADH y los estándares desarrollados por la jurisprudencia. (Nash Rojas, 2013; 489-509)

Este control es, por tanto, la concreción interpretativa y especialmente jurisdiccional de la obligación de garantía consagrada en la CADH (Arts. 1.1 y 2º). Esta obligación de garantía se traduce en la obligación que asume el Estado de organizar todo el aparato de poder público para permitir el pleno y efectivo goce y ejercicio de los derechos y las libertades que se les reconocen en la CADH. Es decir, el Estado se encuentra obligado a crear condiciones efectivas que permitan el goce $\mathrm{y}$ ejercicio de los derechos consagrados en la Convención. Finalmente, se trata de que haya conformidad entre los actos internos y los compromisos internacionales contraídos por el Estado; lo que constituye también otro de los fundamentos del control de convencionalidad en las normas del derecho internacional público, que ha sido recogido por la Corte IDH en el caso Almonacid Arellano vs. Chile (26 de septiembre de 2006, párrafo 125).

Asimismo -agrega Claudio Nash-, la necesidad de realizar un control de 
convencionalidad de las normas emana de los principios del derecho internacional público. En particular, el principio de ius cogens "pacta sunt servanda", consagrado en la Convención de Viena sobre Derecho de los Tratados (1969), como la obligación que tienen los Estados de dar cumplimiento a los tratados de los que son parte, da cuenta del compromiso que deben tener los Estados que han suscrito la $\mathrm{CADH}$, de realizar un control de convencionalidad con el propósito de cumplir con el mandato de protección de los derechos fundamentales. Este imperativo de derecho internacional público debe ser cumplido de buena fe por parte de los Estados. Emana también de los principios del derecho internacional público, el hecho de que los Estados no pueden invocar disposiciones de derecho interno como fundamento para dejar de cumplir compromisos internacionales.

En este sentido, la Corte IDH ha reafirmado que la obligación de tomar todas las medidas necesarias para dar un goce pleno y efectivo a los derechos y libertades consagrados en la Convención, incluye la de adecuar la normativa no convencional existente.

En consecuencia -y siguiendo el criterio de Claudio Nash-, que el fundamento de la figura del control de convencionalidad se base tanto en normas convencionales como en principios del derecho internacional público, otorga un poderoso respaldo jurídico que permite salvar las objeciones que se pueden plantear en torno a la posible restricción a la soberanía de los Estados que supondría la obligación de realizar un control de convencionalidad.

\section{Evolución de la Jurisprudencia de la Corte Interamericana de Derechos Humanos}

La jurisprudencia de la Corte IDH ha pasado por varias etapas en el desarrollo del concepto de control de convencionalidad, y analizar esta evolución es fundamental para entender el actual sentido y alcance de esta labor; a este efecto, resulta muy útil la diferenciación de etapas de evolución de la jurisprudencia interamericana, realizada con gran acierto por el profesor Claudio Nash, en su citado estudio sobre el Control de Convencionalidad.

Se debe recordar, que cuando el juez de la Corte IDH, Sergio García Ramírez, en su voto razonado, en el Caso Myrna Mack Chang c. Guatemala hace por primera vez alusión al control de convencionalidad, se pone de relieve la importancia que tiene para el cumplimiento de las obligaciones internacionales de los Estados el análisis del funcionamiento del Estado en su conjunto y que en este análisis la Corte IDH hace un control de convencionalidad de las actuaciones del Estado:

Para los efectos de la Convención Americana y del ejercicio de la jurisdicción contenciosa de la Corte Interamericana, el Estado viene a cuentas en forma integral, como un todo. En este orden, la responsabilidad es global, atañe al Estado en su conjunto y no puede quedar sujeta a la división de atribuciones que señale el Derecho interno. No es posible seccionar internacionalmente al Estado, obligar ante la Corte solo a uno o algunos de sus órganos, entregar a estos la representación del Estado en el juicio —sin que esa representación repercuta sobre el Estado en su conjunto-y sustraer a otros de este régimen convencional de responsabilidad, dejando sus actuaciones fuera del "control de convencionalidad» que trae consigo la jurisdicción de la Corte internacional. (Corte IDH, caso Myrna Mack Chang c. Guatemala, sentencia de fondo, reparaciones y costas, 25 de noviembre de 2003 , serie $C, n^{\circ} 101$, párr. 29.)

\section{a) Primera etapa}

Existe una primera etapa en que se delinearon los aspectos generales de la figura 
del control de convencionalidad, ocasión en la cual se señaló que el Poder Judicial debe realizar una especie de control de convencionalidad, lo que parece una posición prudente y clarificadora de la naturaleza diversa que tiene esta figura de aquel ejercicio propio del derecho constitucional. Asimismo, se avanza en indicar que este control incluye la interpretación que ha hecho la Corte IDH de las obligaciones internacionales del Estado, lo que es un dato relevante, ya que en muchos sistemas internos ésta es una cuestión muy debatida:

La Corte es consciente de que los jueces y tribunales internos están sujetos al imperio de la ley y, por ello, están obligados a aplicar las disposiciones vigentes en el ordenamiento jurídico. Pero cuando un Estado ha ratificado un tratado internacional como la Convención Americana, sus jueces, como parte del aparato del Estado, también están sometidos a ella, lo que les obliga a velar porque los efectos de las disposiciones de la Convención no se vean mermadas por la aplicación de leyes contrarias a su objeto y fin, $y$ .......Corte IDH, caso Almonacid Arellano y otros c. Chile, sentencia de excepciones preliminares, fondo, reparaciones y costas, 26 de septiembre de 2006, serie C, n. ${ }^{\circ} 154$, párr. 124).

En síntesis -dice Claudio Nash-, aquí están expresados los elementos centrales del control de convencionalidad: i) Existe una obligación del poder judicial de cumplir con la normativa internacional que el Estado ha recepcionado internamente y que por tanto ha pasado a ser parte del sistema normativo interno. ii) Este es un ejercicio hermenéutico que debe buscar la efectividad de los derechos consagrados convencionalmente y evitar que el Estado incurra en responsabilidad internacional. iii) Las normas contrarias a la Convención no pueden tener efectos en el ámbito interno, toda vez que dichas normas incompatibles con las obligaciones internacionales constituyen un ilícito internacional que hace responsable al Estado. iv) Para realizar dicho ejercicio interpretativo el juez debe tener en consideración la jurisprudencia de la Corte IDH (NASH RoJAS, 2013; 496).

\section{b) Segunda etapa}

Avanzando en la evolución de su jurisprudencia, la Corte IDH estableció que el control debe ejercerse incluso de oficio por la magistratura local y aclaró que este se debe hacer dentro del ámbito de competencias y funciones de aquella. Cabe destacar que esta aproximación de la Corte IDH es relevante desde el punto de vista de la legitimidad del sistema, ya que toma en consideración la organización interna del Estado y permite un funcionamiento coherente del sistema. La Corte IDH no impone un sistema, pero sí establece cuáles son las obligaciones que tiene el intérprete, cualquiera sea el sistema constitucional nacional: Cuando un Estado ha ratificado un tratado internacional como la Convención Americana, sus jueces también están sometidos a ella, lo que les obliga a velar porque el efecto útil de la Convención no se vea mermado o anulado por la aplicación de leyes contrarias a sus disposiciones, objeto y fin. En otras palabras, los órganos del Poder Judicial deben ejercer no solo un control de constitucionalidad, sino también «de convencionalidad» ex officio entre las normas internas... (Corte IDH, caso Trabajadores cesados del Congreso («Aguado Alfaro y otros») c. Perú, sentencia de excepciones preliminares, fondo, reparaciones y costas, 24 de noviembre de 2006 , serie $C$, n. ${ }^{\circ} 158$, párr. 128.)

\section{c) Tercera etapa}

En una tercera etapa de análisis, la Corte IDH va más allá y señala que el control de convencionalidad compete a cualquier juez o tribunal que materialmente realice funciones 
jurisdiccionales, incorporando lo que se había señalado anteriormente acerca de la importancia de que este control se realice en el ámbito de competencias de cada magistratura. Esta apertura hacia los órganos competentes para realizar el control, permite la inclusión de los Tribunales Constitucionales y reafirma la idea de que todo juez debe realizar este control con independencia de sus características particulares. Es relevante destacar que este control difuso no lo puede imponer la Corte IDH:

Este Tribunal ha establecido en su jurisprudencia que es consciente de que las autoridades internas están sujetas al imperio de la ley y, por ello, están obligadas a aplicar las disposiciones vigentes en el ordenamiento jurídico. Pero cuando un Estado es Parte de un tratado internacional como la Convención Americana, todos sus órganos, incluidos sus jueces, también están sometidos a aquel...". (Corte IDH, caso Cabrera García y Montiel Flores c. México, sentencia de excepción preliminar, fondo, reparaciones y costas, 26 de noviembre de 2010, serie $C$, n. $^{\circ} 220$, párr. 225.)

Asimismo, en esta sentencia la Corte IDH clarifica cualquier duda que pudiera surgir sobre la naturaleza de esta institución y los alcances propiamente interpretativos de la figura del control de convencionalidad:

"De tal manera, como se indicó en los casos Radilla Pacheco, Fernández Ortega y Rosendo Cantú, es necesario que las interpretaciones constitucionales y legislativas referidas a los criterios de competencia material y personal de la jurisdicción militar en México se adecuen a los principios...es decir el fuero penal ordinario."

\section{d) Cuarta etapa}

En su jurisprudencia más reciente, la Corte IDH incorpora como órgano competente para realizar el control de convencionalidad a toda autoridad pública; es decir, se amplía el espectro desde el Poder Judicial a todos los órganos públicos, a propósito del análisis de la compatibilidad de una ley de amnistía aprobada democráticamente, con las obligaciones que impone la CADH: (...) $L a$ legitimación democrática de determinados hechos o actos en una sociedad está limitada por las normas y obligaciones internacionales de protección de los derechos humanos reconocidos en tratados como la Convención Americana, de modo que la existencia de un verdadero régimen democrático está determinada por sus características tanto formales como sustanciales, por lo que, particularmente en casos de graves violaciones a las normas del derecho internacional de los derechos, la protección de los derechos humanos constituye un límite infranqueable a la regla de mayorías, es decir, a la esfera de lo susceptible de ser decidido por las mayorías en instancias democráticas, en las cuales también debe primar un control de convencionalidad, que es función y tarea de cualquier autoridad pública y no solo del Poder Judicial. (...). (Corte IDH, caso Gelman c. Uruguay, sentencia de fondo y reparaciones, 24 de febrero de 2011, serie $C$, n. $^{\circ} 221$, párr. 239.)

\section{Ámbitos de aplicación del control de convencionalidad}

El control de convencionalidad puede ser desarrollado en dos ámbitos: en el ámbito nacional $y$ en el internacional. a) Precisamente, una de las modalidades en que se desarrolla este tipo de control, se manifiesta en el plano internacional, y se deposita en la Corte IDH que la ha venido desplegando desde el comienzo efectivo de su práctica contenciosa, aunque sólo en época reciente la ha bautizado como "control de convencionalidad". Esto significa que, en el ámbito internacional, es la Corte IDH la que ejerce el control de convencionalidad propiamente tal, esto es, un control que permite la expulsión de las normas contrarias 
a la CADH a partir de los casos concretos que se someten a su conocimiento. Es relevante destacar que, como se ha señalado, esto se hace efectivo, por ejemplo, a través de la supresión de normas locales opuestas a la CADH, como ha ocurrido con la declaración de incompatibilidad de leyes de amnistía con las obligaciones que impone la CADH.

Asimismo, cuando el control se despliega en sede nacional, se encuentra a cargo de los magistrados locales (involucrando también a las demás autoridades públicas -según lo ha entendido recientemente la Corte IDH-) y consiste en la obligación de verificar la adecuación de las normas jurídicas internas que aplican en casos concretos, a la CADH (y otros instrumentos internacionales esenciales en el área de los derechos humanos) y a los patrones interpretativos que el Tribunal Interamericano ha acuñado al respecto, en aras de la cabal tutela de los derechos elementales del ser humano. En resumen, esto significa que se efectúa una interpretación de las prácticas internas, a la luz o al amparo del corpus juris interamericano, que es capital en materia de derechos humanos, acerca del cual aquél ejerce competencia material. Desde este ángulo, el control de convencionalidad es un dispositivo que -en principio y siempre que sea adecuadamente empleado- puede contribuir a la aplicación armónica, ordenada y coherente del derecho vigente en el Estado, abarcando a sus fuentes internas e internacionales. Ciertamente, aquel mecanismo no es inocuo, sino que plantea diferentes retos $\mathrm{y}$, en no pocas ocasiones, genera inconvenientes operativos en los espacios jurídicos nacionales.

En otras palabras, en el ámbito interno, el control de convencionalidad es realizado por los agentes del Estado y principalmente por los operadores de justicia (jueces, fiscales y defensores) al analizar la compatibilidad de las normas internas con la CADH. Sin embargo, las consecuencias de este análisis dependen de las funciones de cada agente estatal $\mathrm{y}$, por tanto, esto no implica necesariamente la facultad de expulsar normas del sistema interno. Un modelo determinado de control de constitucionalidad o convencionalidad no podría ser impuesto por la Corte IDH. Teniendo claro esto -dice Claudio Nash-, podemos afirmar que lo que sí están obligados a hacer los jueces y todos los funcionarios del Estado es a interpretar las normas internas de forma tal que sean compatibles con las obligaciones internacionales del Estado, y que le den efectividad a los derechos consagrados interna $e$ internacionalmente, sea por vía de preferencia de la norma internacional, mediante un ejercicio hermenéutico o por otras vías que pudiera establecer el derecho interno (NASH RoJAS, 2013; 492).

Entonces, considerando los ámbitos en que se puede realizar el control de convencionalidad, es posible sostener que se trata de una figura que viene a concretar la obligación de garantía, mediante un ejercicio hermenéutico que consiste en la verificación que realiza la Corte IDH y todos los agentes estatales, de la adecuación de las normas jurídicas internas a la CADH y a los estándares interpretativos desarrollados en la jurisprudencia de dicho tribunal, aplicando en cada caso concreto aquella interpretación que se ajuste a las obligaciones internacionales del Estado y que dé efectividad a los derechos consagrados convencionalmente.

\section{El ejercicio del Control de Convencionalidad según la Jurisprudencia del Tribunal Constitucional Plurinacional}

La Sentencia Constitucional Plurinacional (SCP) №0487/2014, de fecha 25 de febrero de 2014, en el marco de nuestro sistema constitucional y la interpretación de los derechos y garantías, ha establecido que los jueces, tribunales y autoridades administrativas, tienen el deber de ejercer el control de convencionalidad en nuestro país 
(RIVERA SANTIBÁÑEZ, 2016), de acuerdo al siguiente entendimiento:

Posteriormente, la SCP №0572/2014, de fecha 10 de marzo de 2014, complementa este entendimiento al establecer expresamente que: “(...) tanto el principio de constitucionalidad (art. 410 de la CPE) como el de convencionalidad (arts. 13. IV y 256 de la CPE) -...as normas del bloque de constitucionalidad (...)".

De igual manera, en la SCP №0006/2016, de fecha 14 de enero de 2016 -a tiempo de precisar los criterios para la interpretación de los derechos fundamentales-, se hizo referencia al Control de Convencionalidad para resolver la problemática planteada en el caso; de ahí que, intentando sistematizar la jurisprudencia más relevante sobre el tema, cita la SCP 0783/2015-S1 de 18 de agosto, que con relación al bloque de convencionalidad señaló: Entonces, conforme a la jurisprudencia constitucional vinculante, todas las autoridades, pero sobre todo los jueces y tribunales, están obligados a analizar si las disposiciones legales que aplicarán en los casos concretos, son compatibles con los Pactos Internacionales sobre Derechos Humanos e inclusive con la jurisprudencia emanada de la Corte Interamericana de Derechos Humanos; vale decir, que deben efectuar un verdadero Control de Convencionalidad, garantizando el efectivo goce de los derechos y garantías previstas en la Constitución Política del Estado y las normas del bloque de constitucionalidad. En este punto, cabe poner de relieve que la jurisprudencia interamericana en sentido estricto (esto es, los criterios establecidos por la Corte IDH como intérprete de la Convención Americana y de otros tratados de la región, que han sido acogidos por varios Estados), ha influido crecientemente en los ordenamientos internos. Esa jurisprudencia posee carácter vinculante inter partes, obviamente, en lo que toca a la solución específica de una controversia, pero también erga omnes en lo que atañe a la interpretación de la norma invocada o aplicada, con respecto a los Estados parte en un litigio y a todos los restantes que se hallan bajo el imperio del mismo orden convencional.

La admisión de este último efecto, verdaderamente relevante, ha sido afirmada por el propio Tribunal incluso en lo que concierne a sus opiniones consultivas, cuyo carácter vinculante no fue sostenido en anteriores pronunciamientos. Esta afirmación deriva de las observaciones expresadas por la Corte a propósito del control de convencionalidad, en la Opinión Consultiva OC-21/14, «Derechos y garantías de niñas y niños en el contexto de la migración y/o en necesidad de protección internacional», en cuya oportunidad, la Corte consideró "necesario que los diversos órganos del Estado realicen el correspondiente control de convencionalidad,...de los seres humanos"' (Opinión Consultiva OC-21/14).

\section{El supuesto "Control de Convencionalidad" en la Sentencia Constitucional Plurinacional №0084/2017}

Para finalizar, cabe señalar también que recientemente se ha pronunciado la Sentencia Constitucional Plurinacional №0084/2017, de fecha 28 de noviembre de 2017, en uno de cuyos fundamentos se ha precisado la naturaleza jurídica y características del Control de Convencionalidad, así como su desarrollo jurisprudencial a nivel interamericano. No obstante, y en el marco de la temática propuesta en este trabajo, únicamente interesa poner de relieve que el Tribunal Constitucional Plurinacional lo ha dejado establecido.

En relación a los alcances de la polémica Sentencia Constitucional Plurinacional №0084/2017, y sobre la base de las precisiones anteriormente desarrolladas en este trabajo, acerca del significado y alcance del Control de Convencionalidad, considerando su notable evolución y 
desarrollo en la jurisprudencia interamericana; cabe señalar que si bien es evidente lo afirmado por Eduardo Ferrer Mac Gregor (en su Voto razonado al caso Cabrera García y Montiel Flores vs. México de 2010), en sentido de que el control de convencionalidad en el ámbito interno "convierte al juez nacional en juez internacional: en un primer y auténtico guardián de la Convención Americana... (Lo que equivale a decir que) Los jueces nacionales se convierten en los primeros intérpretes de la normatividad internacional."; ello no puede quedar librado a la discrecionalidad del juez nacional, ni mucho menos puede ser utilizado a conveniencia por un juez constitucional (movido por las circunstancias del caso que le corresponda resolver), porque esa labor interpretativa debe obedecer esencialmente a la necesidad de protección de derechos humanos y fundamentales en un Estado, una vez verificada la incompatibilidad manifiesta entre las normas nacionales y las normas contenidas en la CADH.

Asimismo, no se debe perder de vista, que si bien no existe monopolio alguno en la interpretación de la $\mathrm{CADH}$, quien tiene la calidad de supremo intérprete de la CADH es precisamente la Corte Interamericana de Derechos Humanos (Corte IDH). Por ello, el juez interamericano Ferrer Mac Gregor en su citado Voto razonado, ha dejado establecido que: "no existe duda de que el "control de convencionalidad" debe realizarse por cualquier juez o tribunal que materialmente realice funciones jurisdiccionales, incluyendo, por supuesto, a las Cortes, Salas o Tribunales Constitucionales, así como a las Cortes Supremas de Justicia y demás altas jurisdicciones de los veinticuatro países que han suscrito y ratificado o se han adherido a la Convención Americana sobre Derechos Humanos, y con mayor razón de los veintiún Estados que han reconocido la jurisdicción contenciosa de la Corte IDH, de un total de treinta y cinco países que conforman la OEA."
Cabe hacer notar que en el caso de la SCP №0084/2017, el Tribunal Constitucional Plurinacional ha decidido otorgar una aplicación preferente a un instrumento internacional de protección de los derechos humanos, como es la Convención Americana sobre Derechos Humanos (CADH), al amparo de lo dispuesto por el artículo 256 de la Constitución boliviana; sin embargo, para lograr su objetivo, únicamente ha expuesto argumentos forzados que tergiversan el verdadero sentido y finalidad del Control de Convencionalidad, dado que entre sus fundamentos jurídicos no ha logrado demostrar con argumentos jurídico constitucionales, que dicho instrumento internacional determine la existencia de un derecho humano a ser reelegido (indefinidamente), cuál era el propósito de los accionantes; así como tampoco ha evidenciado que exista algún grado de contradicción o incompatibilidad manifiesta entre las normas de la Constitución, y las disposiciones de la $\mathrm{CADH}$, más aún si se considera que de una simple comparación entre el contenido y alcances de los derechos políticos consagrados en la Ley Fundamental del Estado Plurinacional de Bolivia, frente a los derechos políticos consagrados en la $\mathrm{CADH}$, queda claro que las normas de la Constitución resultan mucho más favorables y amplias en sus alcances para asegurar la eficacia de esos derechos que son vitales para el desarrollo democrático de la sociedad. Entonces, resulta evidente que los supuestos fácticos en los que se debe activar el control de convencionalidad, no se han sustentado de manera suficiente en la reciente Sentencia emitida por el Tribunal Constitucional Plurinacional, que por cierto, fue una decisión emergente del control normativo de constitucionalidad activado a través de la Acción de Inconstitucionalidad abstracta, y que tenía por finalidad esencial, verificar las condiciones de validez formal y material de las normas jurídicas con las disposiciones 
constitucionales y las normas que conforman el bloque de constitucionalidad.

De ahí que, resulta irrazonable la conclusión de aplicar preferentemente una norma internacional como la $\mathrm{CADH}$, cuando no se ha demostrado la existencia de incompatibilidad alguna, o que este instrumento determine la existencia de un derecho humano a ser reelegido (indefinidamente), único supuesto fáctico que, de encontrarse previsto en esa forma, claramente resultaría mucho más favorable (para los intereses particulares de un caudillo, claro está; pero no así para la democracia). Sin embargo, ello no ha sucedido en ese caso, por lo que, el grado de favorabilidad de este instrumento internacional, no es evidente, y tampoco se ha justificado su aplicación preferente. En consecuencia, existe un serio fundamento jurídico -entre muchos otros-, para sostener que se ha emitido una Resolución contraria a la Constitución y las leyes en el Estado Plurinacional de Bolivia, que además ahora se encuentra en riesgo de ser sujeto de responsabilidad internacional por no haber realizado un control (adecuado, razonable e idóneo) de convencionalidad, quebrantando así el orden constitucional y el sistema democrático.

\section{CONCLUSIONES}

En el desarrollo del presente trabajo se ha intentado vislumbrar la trascendental importancia del Bloque de Constitucionalidad que, en el caso de Bolivia, está conformado, además del texto de la Constitución, por todos aquellos tratados, las declaraciones $\mathrm{y}$ convenciones internacionales en materia de derechos humanos que habiendo sido ratificados por el Estado Plurinacional, estén destinados a la promoción, protección y vigencia de los derechos humanos, constituyéndose en un parámetro efectivo de constitucionalidad.

Por otro lado, es importante resaltar que en el marco de la nueva visión del constitucionalismo del Estado Plurinacional de Bolivia, la jurisprudencia constitucional ha realizado un redimensionamiento del Bloque de Constitucionalidad y del Estado Constitucional de Derecho a la luz del pluralismo y la interculturalidad, habiendo insertado en el mismo bloque, los valores plurales y principios supremos rectores del orden constitucional, así como las decisiones jurisdiccionales que emanen del Sistema Interamericano de Derechos Humanos. En consecuencia, y como producto de una interpretación sistemática, extensiva y acorde con el valor axiomático de la Constitución desarrollado por la jurisprudencia constitucional, se ha establecido que el bloque de constitucionalidad imperante en el Estado Plurinacional de Bolivia, está compuesto por diversos elementos que refuerzan su aplicabilidad, dado que además de la Constitución como norma jurídica, los tratados y convenciones internacionales destinados a la protección de los Derechos Humanos, y las normas de Derecho Comunitario ratificadas por el país, también forman parte de este Bloque de Constitucionalidad, las sentencias emitidas por la Corte Interamericana de Derechos Humanos como máximo garante del respeto a los derechos humanos en el plano supranacional, así como los principios y valores plurales supremos inferidos del carácter intercultural y del pluralismo axiomático contemplado en el orden constitucional vigente en Bolivia.

En ese marco, cabe dejar establecido que el Tribunal Constitucional Plurinacional, conforme a su configuración constitucional y a la naturaleza de sus atribuciones, está facultado para realizar el control de constitucionalidad por mandato de la Constitución, pero también está obligado a realizar un adecuado control de convencionalidad por mandato de la Convención y la Corte IDH. Ello significa, que este órgano no se encuentra autorizado para 
declarar la "inaplicabilidad" de normas constitucionales que se hallan vigentes y que son de cumplimiento obligatorio, para gobernantes y gobernados, en virtud de la fuerza normativa de la Constitución; así como tampoco se halla habilitado para declarar la aplicación preferente de un instrumento internacional de protección de los derechos humanos, sin haber sustentado jurídicamente la incompatibilidad manifiesta de dicho instrumento con la normativa interna, o la necesidad de protección de un derecho humano expresamente consagrado, en procura de resguardar el efecto útil de la $\mathrm{CADH}$

\section{REFERENCIAS}

Arango Olaya, M. (2004). El bloque de constitucionalidad en la jurisprudencia de la Corte Constitucional colombiana, p. 1 (Revista Precedente, disponible en: http://bit.ly/1mTdiw2).

Arias López, B. (2012). Fundamentos de la obligatoriedad de las Sentencias de la Corte Interamericana de Derechos Humanos. En: Lex social: revista de los derechos sociales, (№ 1. Págs. 74-94. Disponible en: http://bit.ly/1MuMjEV)

Bazán, V. (2011). Control de convencionalidad, aperturas dialógicas e influencias jurisdiccionales recíprocas. En: Revista Europea de Derechos Fundamentales. ISSN 1699-1524. Núm. 18/2을 Semestre 2011. Páginas 63 - 104. Disponible en: https://dialnet.unirioja.es/servlet/articul o? codigo $=3906378$

Bidart Campos, G. (1995). El Derecho de la Constitución y su fuerza normativa. (Buenos Aires, Ediar), p. 264.

Brewer-Carías, A. R. (2012) "El Control de Convencionalidad, con particular referencia a la garantía del derecho a la protección judicial mediante un recurso sencillo, rápido y efectivo de Amparo de los Derechos Humanos". Texto preparado para la exposición en el evento organizado por la Sala Constitucional de la Corte Suprema de Justicia de Costa Rica, sobre "El control de convencionalidad y su aplicación". San
José, Costa Rica, 27-28 de septiembre de 2012. Disponible en: http://bit.ly/2rpbzn4

Corte Interamericana de Derechos Humanos Ministerio de Relaciones Exteriores de Dinamarca - Danida (2014). Cuadernillo de Jurisprudencia de la Corte Interamericana de Derechos Humanos № 7: Control de Convencionalidad. Pág. 6. Disponible en: http://www.corteidh.or.cr/tablas/r3382 5.pdf

Ferrer Mac-Gregor, E. (2011). "Interpretación conforme y Control Difuso de Convencionalidad. El nuevo paradigma para el juez mexicano". Revista Estudios Constitucionales, Año 9, № 2, pp. 531$622 . \quad$ Disponible en: http://www.scielo.cl/pdf/estconst/v9n2/ art14.pdf

Ferrer Mac-Gregor, E. y Pelayo Möller, C. M. (2012). “La obligación de 'respetar' y 'garantizar' los derechos humanos a la luz de la jurisprudencia de la Corte Interamericana". Revista Estudios Constitucionales, Año 10, № 2, pp. 141 192. Disponible en: http://www.revistasconstitucionales.una m.mx/pdf/3/art/art4.pdf

Ferrer Mac-Gregor, E. y otros (Coords.) (2014). Diccionario de Derecho Procesal Constitucional y Convencional. Tomo I. (México: Poder Judicial de la Federación Instituto de Investigaciones Jurídicas de la Universidad Nacional Autónoma de México). Pág. 233. Disponible virtualmente en: http://biblio.juridicas.unam.mx/libros/li bro.htm?l=3632

García Ramírez, S. (2015). Votos particulares en la Corte Interamericana de Derechos Humanos y reflexiones sobre Control de Convencionalidad. Segunda edición. (México D.F.: Comisión Nacional de los Derechos Humanos). Págs. 26-27.

García Ramírez, S. y Morales Sánchez, J. (2016). Hacia el ius commune interamericano: la jurisprudencia de la Corte IDH en 2013-2016. Anuario Iberoamericano de Justicia Constitucional, №20, 433-463. Disponible en: http://dx.doi.org/10.18042/cepc/aijc.20. $\underline{15}$ 
Ibáñez Rivas, Juana María (2017). Control de Convencionalidad. Colección Estándares del Sistema Interamericano de Derechos Humanos: miradas complementarias desde la Academia. Núm. 1. (México: Instituto de Investigaciones Jurídicas de la Universidad Nacional Autónoma de México - Comisión Nacional de los Derechos Humanos. Págs. 51-68). Libro completo disponible en: https://goo.gl/dJ8KWv

Nash Rojas, Claudio (2013). Control de Convencionalidad. Precisiones conceptuales y desafíos a la luz de la jurisprudencia de la Corte Interamericana de Derechos Humanos. En: Anuario de Derecho Constitucional Latinoamericano - 2013. (Bogotá, Colombia: Fundación Konrad Adenauer). Págs. 489-509.

Rivera Santibáñez, José Antonio (2016). La aplicación del Control de Convencionalidad en Bolivia. En: FUNDACIÓN OBSERVATORIO DE DERECHOS HUMANOS Y JUSTICIA. Reflexiones $\mathrm{y}$ Análisis $\quad \mathrm{N}^{\circ} 3$. Disponible en: http://bit.ly/2lsGH6m

Rubio Llorente, Francisco (1991). El Bloque de la constitucionalidad. Simposium francoespañol de Derecho Constitucional. Universidad de Sevilla, Civitas, Madrid, p. 105.

\section{Jurisprudencia consultada}

Caso Almonacid Arellano vs. Chile. Excepciones Preliminares, Fondo, Reparaciones $y$ Costas. Sentencia de 26 de septiembre de 2006. Serie C No. 154, párr. 123 a 125.

Caso Baldeón García vs. Perú. Fondo, Reparaciones y Costas. Sentencia de 6 de abril de 2006. Serie C No. 147, párr. 140.

Caso Boyce y otros vs. Barbados. Excepción Preliminar, Fondo, Reparaciones y Costas. Sentencia de 20 de noviembre de 2007. Serie C No. 169, párr. 79.

Caso Cabrera García y Montiel Flores vs. México. Excepciones Preliminares, Fondo, Reparaciones y Costas. Sentencia de 26 de noviembre de 2010, párr. 225.

Caso Chocrón vs. Venezuela. Excepción Preliminar, Fondo, Reparaciones y Costas. Sentencia de 1 de julio de 2011. Serie C No. 227, párr. 164, 165 y 172.
Caso Fernández Ortega y Otros vs. México. Excepción Preliminar, Fondo, Reparaciones y Costas. Sentencia de 30 de agosto de 2010. Serie C No. 215, párr. 234.

Caso Fontevecchia y D'Amico vs. Argentina. Fondo, Reparaciones y Costas. Sentencia de 29 de noviembre de 2011. Serie C No. 238, párr. 93, 94 y 113.

Caso Gelman vs. Uruguay. Fondo $y$ reparaciones. Sentencia de 24 de febrero de 2011. Serie C № 221, párr. 193 y 239.

Caso Gomes Lund y Otros (Guerrilha do Araguaia) vs. Brasil. Excepciones preliminares, fondo, reparaciones y costas. Sentencia de 24 de noviembre de 2010. Serie C No. 219, párr. 106.

Caso Heliodoro Portugal vs. Panamá. Excepciones Preliminares, Fondo, Reparaciones y Costas. Sentencia de 12 de agosto de 2008. Serie C No. 186, párr. 180.

Caso Ibsen Cárdenas e Ibsen Peña vs. Bolivia. Fondo, Reparaciones y Costas. Sentencia de $1^{\text {o }}$ de septiembre de 2010. Serie C No. 217, párr. 202.

Caso La Cantuta vs. Perú. Fondo, Reparaciones y Costas. Sentencia de 29 de noviembre de 2006. Serie C No. 162, párr. 173.

Caso López Mendoza vs. Venezuela. Fondo, Reparaciones y Costas. Sentencia de 1 de septiembre de 2011. Serie C No. 233, párr. 226-228.

Caso Manuel Cepeda Vargas vs. Colombia. Excepciones Preliminares, Fondo $y$ Reparaciones. Sentencia de 26 de mayo de 2010. Serie C No. 213, párr. 208, nota 307.

Caso Rosendo Cantú y Otra vs. México. Excepción Preliminar, Fondo, Reparaciones y Costas. Sentencia de 31 de agosto de 2010. Serie C No. 216, párr. 219.

Caso Rosendo Radilla Pacheco vs. Estados Unidos Mexicanos. Excepciones Preliminares, Fondo, Reparaciones $y$ Costas. Sentencia de 23 de noviembre de 2009. Serie C No. 209, párr. 339.

Caso Tibi vs. Ecuador, de 7 de septiembre de 2004, párr. 3;

Caso Tibi vs. Ecuador. Excepciones Preliminares, Fondo, Reparaciones $y$ Costas. Sentencia de 7 de septiembre de 2004.

Caso Trabajadores Cesados del Congreso (Aguado Alfaro y otros) vs. Perú. 


\section{Excepciones Preliminares, \\ Excepciones Preliminares, Fondo, Reparaciones y Costas. Sentencia de 24 de noviembre de 2006. Serie C No. 158, párr. 128.}

Caso Vargas Areco vs. Paraguay, párr. 6 y 12.

Caso Vélez Loor vs. Panamá. Excepciones preliminares, fondo, reparaciones y costas. Sentencia de 23 de noviembre de 2010. Serie C No. 218, párr. 287.

Caso Ximenes Lopes vs. Brasil. Fondo, Reparaciones y Costas. Sentencia de 4 de julio de 2006. Serie C No. 149, párr. 172

Casos Myrna Mack Chang vs. Guatemala, resuelto el 25 de noviembre de 2003, párr. 27;

Comunidad Indígena Xákmok Kásek vs. Paraguay. Fondo, Reparaciones y Costas. Sentencia de 24 de agosto de 2010. Serie C No. 214, párr. 311

Opinión Consultiva OC-21/14, «Derechos y garantías de niñas y niños en el contexto de la migración y/o en necesidad de protección internacional», 19 de agosto de 2014, párr. $110-114,150,280,123-$ 149. Disponible en: http://www.Corte IDH.or.cr/docs/opiniones/resumen_serie a_21_esp.pdf Citado por: GARCÍA RAMÍREZ, Sergio y MORALES SÁNCHEZ, Julieta. Hacia el ius commune interamericano: la jurisprudencia de la Corte IDH en 2013-2016. Anuario Iberoamericano de Justicia Constitucional 2016, №20, 433-463. Disponible en: http://dx.doi.org/10.18042/cepc/aijc.20. $\underline{15}$
Opinión Consultiva OC-14/94, Responsabilidad Internacional por Expedición y Aplicación de Leyes Violatorias de la Convención (Arts. 1 y 2 Convención Americana Sobre Derechos Humanos), del 9 de diciembre de 1994, Serie A No. 14, párr. 35

Sentencia Constitucional №0058/2003, de 25 de junio.

Sentencia Constitucional №0491/2003-R, de 15 de abril.

Sentencia Constitucional $N^{\circ} 1888 / 2011-\mathrm{R}$, de 7 de noviembre.

Sentencia Constitucional N¹907/2011-R, de 7 de noviembre.

Sentencia Constitucional Plurinacional №1227/2012, de 7 de septiembre.

Sentencia Constitucional Plurinacional №1250/2012, de 20 de septiembre.

Sentencia Constitucional Plurinacional №0487/2014, de 25 de febrero.

Sentencia Constitucional Plurinacional №0572/2014, de 10 de marzo.

Sentencia Constitucional Plurinacional №0006/2016, de 14 de enero.

Sentencia Constitucional Plurinacional №0783/2015-S1, de 18 de agosto.

Sentencia Constitucional Plurinacional №0084/2017, de 28 de noviembre.

Voto Razonado del Juez ad hoc Eduardo Ferrer Mac-Gregor Poisot, en relación con la Sentencia de la Corte Interamericana de Derechos Humanos en el Caso Cabrera García y Montiel Flores vs. México, de 26 de noviembre de 2010. 